\title{
Strain Aging in Boron Alloyed Multi-Phase C- Mn - Si - Steel Wire Rod
}

\author{
Anatoliy Nesterenko ${ }^{2}$, Alexander Sychkov ${ }^{1}$, Valeriy Plyuta ${ }^{2} \&$ Mikhail Blokhin $^{1}$ \\ ${ }^{1}$ Nosov Magnitogorsk State Technical University, Magnitogorsk, Russia \\ ${ }^{2}$ Iron and Steel Institute of the National Ukrainian Academy of Sciences, Dnipro, Ukraine \\ Correspondence: A. B. Sychkov, Nosov Magnitogorsk State Technical University, Magnitogorsk, Russia. E-mail: \\ absychkov@mail.ru
}

Received: May 12, 2017

Accepted: May 24, 2017

Online Published: June 30, 2018

doi: $10.5539 /$ jmsr.v7n3p78

URL: https://doi.org/10.5539/jmsr.v7n3p78

\begin{abstract}
The specimens of $\mathrm{C}-\mathrm{Mn}-\mathrm{Si}$ - steel wire rod $5.5 \mathrm{~mm}$ in diameter with $0.005 \% \mathrm{~B}$ and without $\mathrm{B}$ additions from Moldova Steel Works had been studied. It was been established by crystallographic-geometrical analysis, that the boron atoms could be allocate in $\mathrm{B}-$ alloyed $\alpha-\mathrm{Fe}$ only in the positions of a sub-interstitial solid solution. By study a static strain aging (SSA) and a dynamic strain aging (DSA) specimens of wire rod by $\mathrm{C}-\mathrm{Mn}-\mathrm{Si}$ - steel with B and without B (both with multi-phase (ferrite- martensite (bainite)-pearlite) microstructures) more expressed decreasing of strengthening properties and higher characteristics of ductility had been determined for $\mathrm{C}$ - Mn - Si - steel specimens with B. These results could be explained by "de - nitrogenous" and "de - carbonaceous" mechanisms, when boron atoms from $\alpha-\mathrm{Fe}$ sub-interstitial solid solution by producing wire rod and by its strain aging thermal treatment with temperatures $150-450{ }^{\circ} \mathrm{C}$ generate boron- nitrogenous and boron - carbonaceous nitrogenous precipitations. By realizing these mechanisms nitrogen and carbon atoms are partly excluded from the dislocation pinning's process. This, in fact, explains to inhibit the development of strain aging (SSA and DSA) in boron- micro-alloyed $\mathrm{C}-\mathrm{Mn}-\mathrm{Si}$ - steel.
\end{abstract}

Keywords: static and dynamic strain aging, wire rod, boron micro-alloyed steel, mechanical properties.

\section{Introdaction}

It was showed in (Frank \& Kirkcaldy, 1998; Yalamanchili, Nelson, Power, \& Lanham, 2001; Parusov., Sychkov, Zhigarev, \& Perchatkin, 2004), that metal-roll of boron - micro-alloyed low - carbon and low-alloyed steels was characterized by a high level of ductility and deformability. Mechanical and physical properties of boron - microalloyed low - carbon and low-alloyed steels are determined to a large degree the peculiarities of boron atoms' disposition in the crystalline lattices of iron's $\gamma$ - and $\alpha$-phases (austenite and ferrite, respectively). A comparison the sizes of the octahedral and tetrahedral voids in the crystalline lattices of $\gamma-$ and $\alpha-F e$ with size of a boron atom $\left(\mathrm{r}_{\mathrm{B}}=0.091 \mathrm{~nm}\right)$ was showed (Table 1, data of (Lyakishev, Pliner \& Lappo, 1986), that the boron atom, whose size in 1.26 times surpasses the size of nitrogen atom and in 1.18 times - the size of carbon atom, whether could be allocate in the positions of an interstitial solid solution (in the octahedron and tetrahedron voids) in both iron's modifications.

However, accordingly data, for instance, in Table 2 (McBride, Spretnak, \& Speiser, 1954), boron atoms have a decided solubility in $\gamma$ - and $\alpha-$ Fe. Data of the X-ray structure analysis were showed (Shevelev, 1966), that a crystalline lattice parameter $\boldsymbol{a}$ of the B - alloyed $\alpha$ - Fe had a lower value, than such in $\alpha$-Fe without B. As it in (Shevelev, 1966) was stated the boron atoms could be allocate only in the positions of a sub-interstitial solid solution in B - alloyed $\alpha-\mathrm{Fe}$.

A thermodynamically steady solid solution was found out (Brown, Garnish, \& Honeycombe, 1974) in boron alloyed $\alpha-$ Fe by the method of autoradiography. A Snoek peak was not detected in internal-friction measurements, indicating that boron is not in an interstitial solid solution in $\alpha-$ Fe. Therefore authors (Brown, Garnish, \& Honeycombe, 1974) asserted, that boron generate in $\alpha-F e$ a sub-interstitial solid solution, but in $\gamma$ - Fe, possibly, - an interstitial solid solution.

However, the changing of the lattice parameter $\boldsymbol{a}$ of $\gamma-\mathrm{Fe}$ (without B and with adding 0.005 wt. \% by B) in temperature interval $925 \ldots 1200^{\circ} \mathrm{C}$ showed (Figure 1, data of (Mirkin, 1979)), that by all temperatures of this interval the lattice parameter $\boldsymbol{a}$ of the boron - alloyed $\gamma$ - Fe had a lower value, than such in $\gamma$ - Fe without B. As the case stands it means, that only a sub-interstitial solid solution in $\gamma$ - Fe could be generated by boron. 
Table 1. Size's parameters of Fe -, N -, C -, B - atoms, of octahedral and tetrahedral voids of $\alpha$ - and $\gamma-\mathrm{Fe}-$ lattices (Lyakishev, Pliner \& Lappo, 1986)

\begin{tabular}{cccccccc}
\hline \multicolumn{3}{c}{ Atomic radius, $\mathbf{n m}$} & \multicolumn{4}{c}{ Void's radius, $\mathbf{n m}$} \\
\cline { 5 - 9 } & & & & \multicolumn{2}{c}{$\boldsymbol{\gamma}$ - $\boldsymbol{F e}$} & \multicolumn{2}{c}{$\boldsymbol{\alpha}$ - $\boldsymbol{F e}$} \\
$\mathrm{Fe}$ & $\mathrm{N}$ & $\mathrm{C}$ & $\mathrm{B}$ & octahedral & tetrahedral & octahedral & tetrahedral \\
\hline 0.127 & 0.072 & 0.077 & 0.091 & 0.053 & 0.029 & 0.019 & 0.036 \\
\hline
\end{tabular}

Table 2. A boron solubility in $\gamma$ - and $\alpha-F e$ (McBride, Spretnak \& Speiser, 1954)

\begin{tabular}{ccccccccc}
\hline $\begin{array}{c}\text { Mo- } \\
\text { difi- } \\
\text { cation }\end{array}$ & 1131 & 1049 & 949 & 915 & 906 & 837 & 794 & 710 \\
\hline $\boldsymbol{\gamma}-\boldsymbol{F e}$ & 0.0182 & 0.0061 & 0.0034 & 0.0024 & 0.0020 & - & - & - \\
$\boldsymbol{\alpha}-\boldsymbol{F e}$ & - & - & - & - & 0.0082 & 0.0061 & 0.0011 & 0.0002 \\
\hline
\end{tabular}

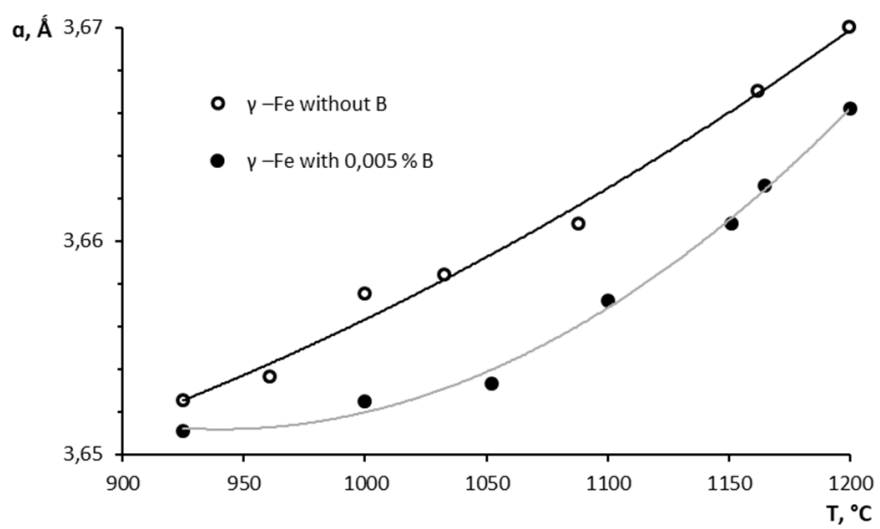

Figure 1. Changing of crystalline lattice parameter $\boldsymbol{a}$ of $\gamma-F e$ (without B and with 0.005 wt. \% by B) in temperature interval $925 \ldots 1200^{\circ} \mathrm{C}$ (Mirkin, 1979)

Strain aging is commonly referred to as a change in properties of metals after cold or hot (warm) working (Babich, Gul \& Dolzhenkov, 1972). Its key effects are hardening and embrittlement of steels and alloys. They can be observed in deformed steels during its soaking at ambient temperatures or thermal activation temperatures (normally, at $100-500{ }^{\circ} \mathrm{C}$ ) - static strain aging (SSA), and during deformation of steels - dynamic strain aging (DSA). The mechanism of strain aging is based on effects of dislocation pinning by impurity atoms (primarily carbon, $\mathrm{C}$, and nitrogen, $\mathrm{N}$ ).

Aging of steels, on the one part, leads to adverse implications, such as loss of ductility and toughness and certain instability of properties of steels over time (Babich, Gul, \& Dolzhenkov, 1972). To mitigate these effects technological solutions and methods are being studied with the aim to inhibit the development of strain aging processes in steels. On the other part, aging is employed as a type of hardening treatment. For instance, recently in automotive manufacturing bake hardening (BH) process is used (Calcagnotto, Adfachi, Ponge, \& Raabe, 2014). $\mathrm{BH}$ process is in active during automotive paint baking. Consequently, it is factually the implementation of SSA in cold deformed (after press forming) automotive parts. Authors (Calcagnotto, Adfachi, Ponge \& Raabe, 2014) simulated BH process in dual-phase (DP - ferrite - martensite) sheets by steel of composition (in wt. \%): $0.17 \mathrm{C}$; $1.49 \mathrm{Mn} ; 0.22 \mathrm{Si} ; 0.0031 \mathrm{~S} ; 0.0011 \mathrm{P} ; 0.033 \mathrm{Al} ; 0.0033 \mathrm{~N}$. To simulate $\mathrm{BH}$ process the specimens of DP sheets with ultra fine ferrite grains (UFG) (ferrite grain size $\boldsymbol{d}_{F G}=1.2 \mu \mathrm{m}$ ) were aged at $170^{\circ} \mathrm{C}$ for $20 \mathrm{~min}$ in a vacuum furnace. Aging at $170{ }^{\circ} \mathrm{C}$ (bake hardening) of the UFG DP steel leaded to a strong increase in $\boldsymbol{Y S}$ and small decrease in $\boldsymbol{T S}$ (Table 3). Plasticity was enhanced in term of total elongation $\boldsymbol{E} \boldsymbol{l}$. Reduction in area $\boldsymbol{R} \boldsymbol{A}$ was improved by $22 \%$ (from $15.3 \%$ to $37.5 \%$ - Table 3). These effects were attributed to dislocation's locking, relaxation of internal stress, reduction of supersaturated interstitial carbon and nitrogen and tempering effects in martensite (Calcagnotto, Adfachi, Ponge, \& Raabe, 2014).

A development of new combinations of steels composition and conditions of their deformation and thermal treatment is particularly important for steel products that are further subjected to cold deformation, such as wire 
rod of carbon-alloyed and low-alloyed steels for commercial wire drawing. Even though numerous studies have been conducted in this field, many issues connected with the influence of B - micro-additions, in particular, on mechanical properties of low-alloyed steel wire rod during strain aging has remained uninvestigated at all thus making this research very important.

\section{Materials and Research Techniques}

The steel's object employed in the investigation was $\mathrm{C}-\mathrm{Mn}-\mathrm{Si}$ - steel wire rod $5.5 \mathrm{~mm}$ in diameter without $\mathrm{B}$ (heat 1 ) and with $0.005 \%$ B additions (heat 2) from Moldova Steel Works. The Table 4 below shows chemical compositions of the $\mathrm{C}-\mathrm{Mn}-\mathrm{Si}$ - steel heats under study. Optical microscopy method (light microscope "Axiovert 200 M MAT") was used by study structures of wire rod's specimens. The parameters of fine crystalline structure in these specimens - levels of the broadening of X-ray interferences, micro-deformation $\Delta \mathbf{a} / \mathbf{a}$ in $\alpha$ - Fe - crystalline lattice and dislocation's destiny $\rho$ in $\alpha-\mathrm{Fe}$ (ferrite) were determined by X-ray diffraction method of approximations (Gorelik, Skakov \& Rastoguev, 1994). X-ray diffraction analysis of wire rod's specimens was realized by computerized diffractometer DRON - UM1.

Table 3. Volume of martensite and mechanical properties of UFG DP steel (Calcagnotto, Adfachi, Ponge \& Raabe, 2014)

\begin{tabular}{cccccc}
\hline Type of & Volume of & Yield strength & Tensile strength & \multicolumn{2}{c}{ Total elongation } \\
DP-steel & martensite, $\%$ & $\boldsymbol{Y S}, \mathrm{MPa}$ & $\boldsymbol{T S}, \mathrm{MPa}$ & $\boldsymbol{E L}, \%$ & $7.3 \pm 4$ \\
\hline UFG & 29.8 & $525 \pm 8$ & $1037 \pm 16$ & $\boldsymbol{R} \boldsymbol{A}, \%$ & $15.3 \pm 4.0$ \\
UFG BH & 28.2 & $619 \pm 6$ & $1005 \pm 5$ & $11.4 \pm 1.5$ & $37.5 \pm 0.9$ \\
\hline
\end{tabular}

Table 4. Chemical composition of tested heats

\begin{tabular}{lccccccccccc}
\hline Heat & \multicolumn{10}{c}{ Fraction of elements, wt. \% } \\
\cline { 2 - 14 } number & $\mathrm{C}$ & $\mathrm{Mn}$ & $\mathrm{Si}$ & $\mathrm{S}$ & $\mathrm{P}$ & $\mathrm{Cr}$ & $\mathrm{Ni}$ & $\mathrm{Cu}$ & $\mathrm{Al}$ & $\mathrm{N}$ & $\mathrm{B}$ \\
\hline 1 & 0.07 & 1.87 & 0.78 & 0.003 & 0.011 & 0.04 & 0.09 & 0.15 & 0.0045 & 0.008 & - \\
2 & 0.07 & 1.79 & 0.75 & 0.002 & 0.012 & 0.05 & 0.10 & 0.19 & 0.0010 & 0.008 & 0.005 \\
\hline
\end{tabular}

The experiment for study SSA in C - Mn - Si - steel wire rod $5.5 \mathrm{~mm}$ in diameter without $\mathrm{B}$ and with $0.005 \% \mathrm{~B}$ additions $\mathrm{B}$ (heats 1 and 2, respectively, Table 4 ) included a preliminary deformation with a residual elongation $6 \%$ and an aging at temperature $200^{\circ} \mathrm{C}$ in due 1 hour.

In the experiment for study an effect of DSA specimens by investigated steel's wire rods were subjected to tensile tests at room temperature (to determine the original level of mechanical properties of specimens) and at temperatures from $100{ }^{\circ} \mathrm{C}$ to $500{ }^{\circ} \mathrm{C}$ on a tensile testing machine fitted with a high temperature accessory. The specimens were held at the test temperature for 15 minutes and then subjected to tensioning at the rate of $2 \mathrm{~mm} / \mathrm{min}$.

\section{Results and Discassions}

As shown by the microstructure analysis, hot-rolled $\mathrm{C}-\mathrm{Mn}-\mathrm{Si}$ - steel wire rod with and without $\mathrm{B}$ additions originally had a multi-phase microstructure consisting of a polygonal ferrite matrix (ferrite grain size $\boldsymbol{d}_{\boldsymbol{F} G}=15$ $17 \mu \mathrm{m}$, № 10 (ASTM)) with evenly distributed pearlite and martensite (bainite) islands (Figure 1).

The results of experiment for study SSA were showed, that SSA in C - Mn - Si - steel wire rod with $0.005 \% \mathrm{~B}$ developed less intensive, than in such wire rod by steel without B. The decrement of strengthening properties (tensile strength $\boldsymbol{T S}$ and yield strength $\boldsymbol{Y S}$ ), induced by SSA in C - Mn - Si - steel wire rod with $0.005 \%$ B was more significantly, than in such wire rod without B. A difference between the decrement of strengthening properties was more expressed for $\boldsymbol{T S}: \boldsymbol{\Delta T S}=-52 \mathrm{MPa}$ because for $\boldsymbol{Y S}: \boldsymbol{\Delta} \boldsymbol{Y S}=-11 \mathrm{MPa}$. These results showed a weakened influence of the boron - micro-alloying on strengthening properties of $\mathrm{C}-\mathrm{Mn}-\mathrm{Si}$ - steel wire rod by SSA. Less development of SSA in steel with B was explained by realizing "de - nitrogenous" and "de carbonaceous" mechanisms, when boron atoms from the $\alpha-\mathrm{Fe}$ sub-interstitial solid solution by producing wire rod (the first step of binding effect) and by its strain aging thermal treatment (the second step of binding effect) bind nitrogen and carbon atoms in boron- nitrogenous and boron - carbonaceous - nitrogenous precipitations. Most part of these precipitations wouldn't be so small for the effect of dispersion hardening. 
Special chemical analysis showed that in $\alpha-\mathrm{Fe}$ solid solution of hot-rolled $\mathrm{C}-\mathrm{Mn}-\mathrm{Si}$ - steel wire rod with $0.005 \% \mathrm{~B}$ (heat 2, Table 4) content of free (don't bind) nitrogen atoms was $0.004 \%$, but in hot-rolled C $-\mathrm{Mn}-\mathrm{Si}$ - steel wire rod without B (heat 1, Table 4 ) $-0.008 \%$. It means that by producing in $\mathrm{C}-\mathrm{Mn}-\mathrm{Si}$ - steel wire rod with $0.005 \%$ B approximately $50 \%$ of nitrogen atoms were bound by boron - nitrogenous and boron - carbonaceous - nitrogenous precipitations. This fact and above mentioned "binding effect" by aging (the second step of binding effect) inhibit developing of SSA in $\mathrm{C}-\mathrm{Mn}-\mathrm{Si}$ - steel wire rod with $\mathrm{B}$.

The results of X-ray diffraction study showed that levels of the broadening of X-ray interferences, microdeformations $\Delta \mathbf{a} / \mathbf{a}$ in $\alpha$ - Fe - crystalline lattice and dislocation's destiny $\boldsymbol{\rho}$ in $\alpha-\mathrm{Fe}$ (ferrite) of hot-rolled $\mathrm{C}-\mathrm{Mn}$ - Si - steel wire rod with B were lower than such in hot-rolled C - Mn - Si - steel wire rod without B (Table 5). These results could be explained in the first place by realizing "de - nitrogenous" and "de - carbonaceous" mechanisms in hot-rolled $\mathrm{C}-\mathrm{Mn}-\mathrm{Si}$ - steel wire rod with B (above mentioned the first step of "binding effect" by producing).

In the experiment for study an effect of DSA in specimens of C - Mn - Si - steel wire rod without B and with B additions (heats 1 and 2, respectively, Table 4) a steady reduction in tensile strength properties is virtually observed for all test temperatures (Figure 3) rather than an increase, which is typical for carbon steels with ferrite - pearlite structures (Babich, Gul \& Dolzhenkov, 1972). The only exclusion is the positive change of $\boldsymbol{T S}$ at $350^{\circ} \mathrm{C}$ compared to the initial values of the wire rod without $\mathrm{B}$ additions (Figure $3 \mathrm{a}$ ).

Apparently, steady loss of $\boldsymbol{T S}$ and $\boldsymbol{Y S}$ at $100-120^{\circ} \mathrm{C}$ (Figure 3) is associated with decreasing a strained state's level in steels that are stipulated by the strain's relocation between the structure fractures of $\mathrm{C}-\mathrm{Mn}-\mathrm{Si}$ - steel wire rod - ferrite, pearlite and martensite (bainite) (Figure 2), with reduction of supersaturated interstitial carbon and nitrogen and tempering effects in martensite (bainite). Notably the effects similar to such in UFG DP steel sheets at $170{ }^{\circ} \mathrm{C}$ aging (bake hardening) (Calcagnotto, Adfachi, Ponge \& Raabe, 2014) were implemented. Small increasing of strengthening properties by temperatures $150-450^{\circ} \mathrm{C}$ (Figure 3 ) was caused by break-up's effect in martensite (bainite), increasing dislocation's locking and generating a lot of new sub-micro- precipitations. One part of these precipitations had very small size and could be inhibit the dislocation's flow in steels.

The trend of ductility is of interest. The variation of the total elongation $\boldsymbol{E} \boldsymbol{L}_{100}$ with temperature slightly differs between $\mathrm{C}-\mathrm{Mn}-\mathrm{Si}$ - steel wire rod with B and without B, but level of $\boldsymbol{E} \boldsymbol{L}_{100}$ permanently was higher for wire rod with B (Figure 4 a). Values of the reduction in area $\boldsymbol{R} \boldsymbol{A}$ observed in the wire rod with B at a consistent high level of $77-80 \%$ at $200-450{ }^{\circ} \mathrm{C}$ (Figure $4 \mathrm{~b}$ ), which is the most dangerous range of temperatures affecting plasticity and drawability of the steel. Apparently, it is the key factor that accounts for the high deformability of this wire rod, which can be observed under the conditions of commercial production. As can be seen in the same Figure 4 $\mathrm{b} \mathrm{C}-\mathrm{Mn}-\mathrm{Si}$ - steel wire rod without $\mathrm{B}$ has a lower level of $\boldsymbol{R} \boldsymbol{A}$.

In the current literary sources there are the controversial points on the subject of changing of dual- phase (DP ferrite - martencite (bainite)) steels mechanical properties by DSA - process. So, in (Shahriary, Koohbor, Ahadi, Ekrami, Khakian-Qomi \& Izadyar, 2012) was researched specimens of AISI 4340 steel bars with DP microstructure imposed a $3 \%$ pre-strain at the temperature range of $150-450{ }^{\circ} \mathrm{C}$ and its the room temperature tensile tests were carried out, afterwards. Results indicated that the maximum values for both $\boldsymbol{Y S}$ and $\boldsymbol{T S}$ would exist for the pre-strained samples at the temperature range of $250-300^{\circ} \mathrm{C}$. Also, a sudden drop of the ductility was observed at the mentioned temperature range. The observed properties' behavior might be attributed to the DSA process that took place at this temperature range. Queiroz et al. (Queiroz, Cunha \& Gonzalez, 2012) revealed too a significant strengthening and loss in ductility of DP - steel - specimens between $200-400{ }^{\circ} \mathrm{C}$ by its tensile tests at the temperature range of $150-450{ }^{\circ} \mathrm{C}$. Queiroz et al. Authors (Queiroz, Cunha \& Gonzalez, 2012) linked this properties' behavior to the DSA phenomena. On the other hand, authors (Bayramin, Şimşir \& Efe, 2017) determined, that mechanical testing of DP590 and DP800 steels between room temperature $-400^{\circ} \mathrm{C}$ revealed two types of strain aging behavior for given temperature range. Both grades of the steels demonstrated a slight softening of $\boldsymbol{T S}$ and minimal loss in total ductility up to $100^{\circ} \mathrm{C}$. At $400^{\circ} \mathrm{C}$ testing softening both grades of the steels was significant, notably $\boldsymbol{T S}$ decreased considerably. At $200-300^{\circ} \mathrm{C}$ - testing the increasing of $\boldsymbol{T S}$ took place, what caused a significant drop in ductility. Special authors' research proved (Bayramin, Şimşir, \& Efe, 2017), that both DP590 and DP800 steels strain aging behavior for given temperature range of $150-450^{\circ} \mathrm{C}$ linked to the DSA process.

Above mentioned data testified, that $\mathrm{C}-\mathrm{Mn}-\mathrm{Si}$ - steel with $\mathrm{B}$ - adding and $\mathrm{MP}$ - microstructures has been shown the different mechanical properties' behavior by DSA because of realizing boron - "de - nitrogenous" and "de carbonaceous" both mechanisms then such AISI 4340 (with DP - microstructure), DP590 and DP800 steels (all without B - adding). 
Table 5. The parameters of fine crystalline structure in the investigated specimens

\begin{tabular}{ccccc}
\hline Kind of C-Mn-Si- & \multicolumn{1}{c}{ Broadening of X-ray interferences, radian $\times 10^{-3 *}$} & & $\Delta \mathbf{a} / \mathbf{a} \times 10^{-3}$ & \multirow{\rho}{}{${ }^{-3} \times 10^{10} \mathrm{~cm}^{-2}$} \\
\cline { 2 - 3 } steel's specimens & $(110)$ & $(220)$ & & 0.98 \\
\hline Without B & 1.990 & 12.313 & 0.93 & 1.96 \\
With $0.005 \%$ B & 1.799 & 11.725 & 1.78 \\
\hline
\end{tabular}

*(110) and (220) interferences' of steel's $\alpha-$ Fe solid solution (ferrite) were gained by using Fe - X-ray radiation.

\section{Conclusions}

The specimens of $\mathrm{C}-\mathrm{Mn}-\mathrm{Si}$ - steel wire rod $5.5 \mathrm{~mm}$ in diameter with $0.005 \% \mathrm{~B}$ and without $\mathrm{B}$ additions from Moldova Steel Works has been studied. It was been established by crystallographic-geometrical analysis, that the boron atoms could be allocate in B - alloyed $\alpha-\mathrm{Fe}$ only in the positions of a sub-interstitial solid solution. The higher characteristics of ductility $\left(\boldsymbol{E} \boldsymbol{L}_{100}, \boldsymbol{R} \boldsymbol{A}\right)$ and more expressed decreasing of strengthening properties in microalloyed by boron $\mathrm{C}-\mathrm{Mn}-\mathrm{Si}$ - steel wire rod versus such wire rod by $\mathrm{C}-\mathrm{Mn}-\mathrm{Si}$ - steel without boron (both with MP - microstructures) could be explained by "de - nitrogenous" and "de - carbonaceous" mechanisms, when boron atoms from the $\alpha-\mathrm{Fe}$ sub-interstitial solid solution by producing wire rod and by its strain aging thermal treatment at temperatures $150-450{ }^{\circ} \mathrm{C}$ generate boron- nitrogenous and boron - carbonaceous - nitrogenous precipitations. By realizing these mechanisms nitrogen and carbon atoms are partly excluded from the dislocation pinning's process. This, in fact, explains to inhibit the development of strain aging (SSA and DSA) in boron - micro-alloyed $\mathrm{C}-\mathrm{Mn}-\mathrm{Si}-$ steel.

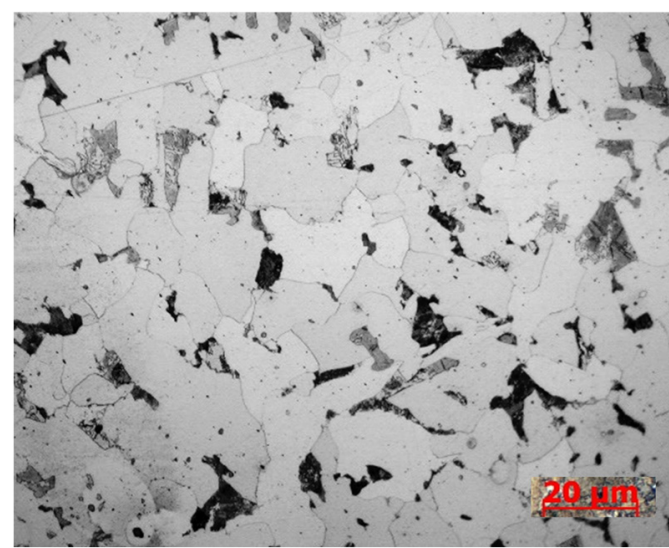

a

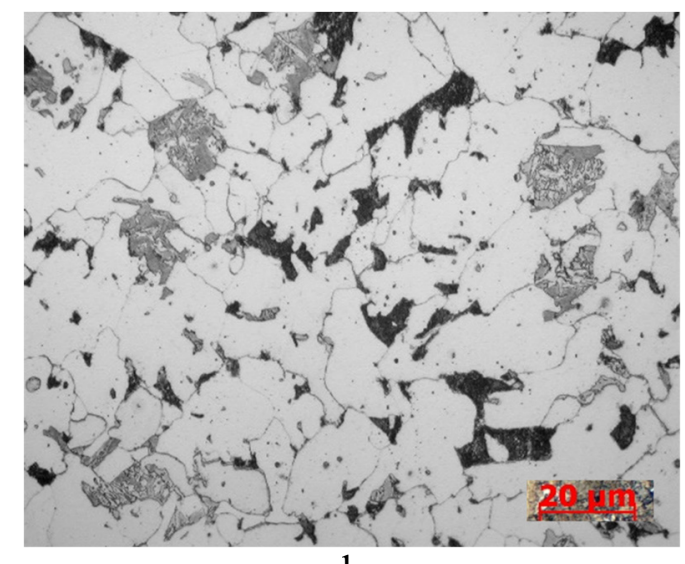

b

Figure 2. Microstructure of wire rod by $\mathrm{C}-\mathrm{Mn}-\mathrm{Si}$ - steel without $\mathrm{B}$ (a) and with $\mathrm{B}$ - adding (b)

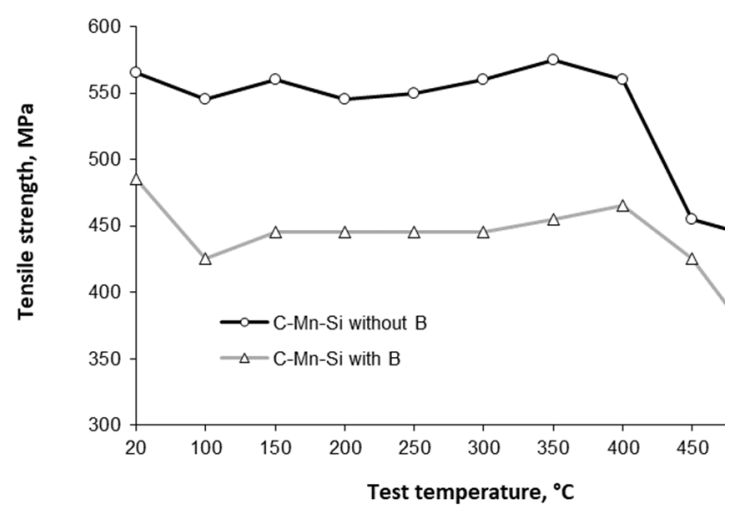

$\mathrm{a}$

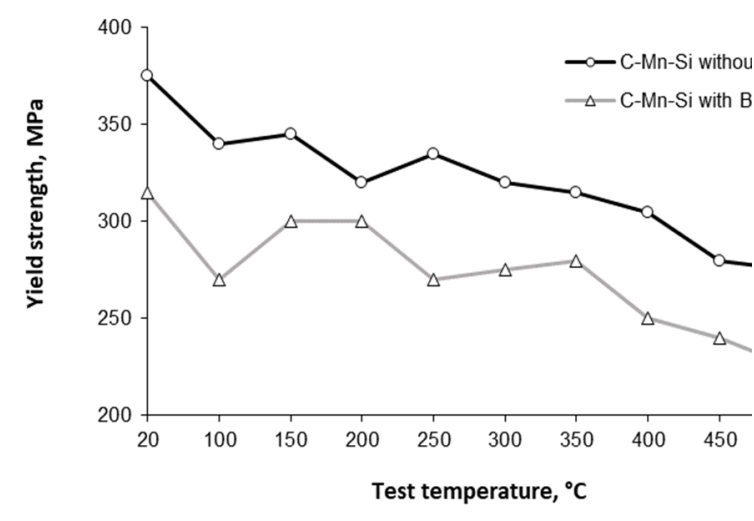

b

Figure 3. The relationship between tensile test temperature and both TS $(a)$ and $Y S(b)$ for 5.5-mm-diameter wire rod by $\mathrm{C}-\mathrm{Mn}-\mathrm{Si}$ - steel with $\mathrm{B}$ and without $\mathrm{B}$ 


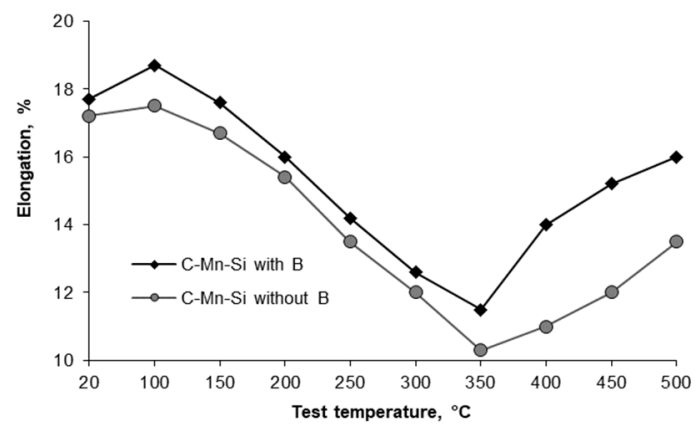

a

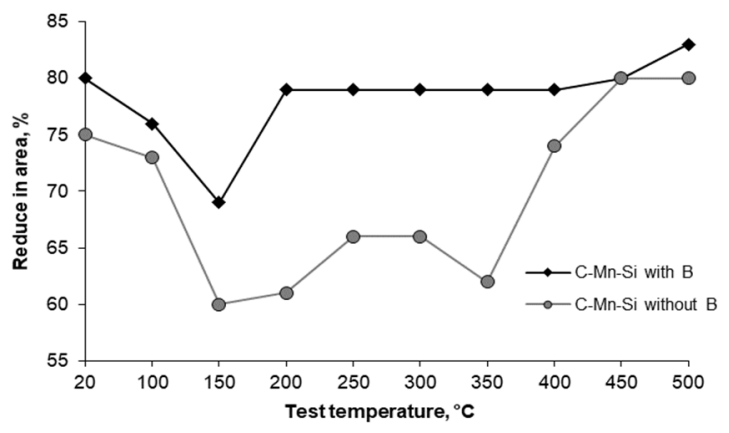

b

Figure 4. An influence of tensile test temperatures on characteristics of ductility $E L_{100}(a)$ and $R A(b)$ in $5.5-\mathrm{mm}$ diameter wire rod by $\mathrm{C}-\mathrm{Mn}-\mathrm{Si}$ - steel with $\mathrm{B}$ - adding and without $\mathrm{B}$

\section{References}

Babich, V. K., Gul, Y. P., Dolzhenkov, I. E. (1972). Strain Aging of steel. Moskow: Metallurgy (in Russian).

Bayramin, B., Şimşir, C., \& Efe, M. (2017). Dynamic Strain Aging in DP Steels at Forming Relevant Strain Rates and Temperatures. Materials Science and Engineering A. http://dx.doi.org/10.1016/j.msea.2017.08.006

Brown, A., Garnish, J. D., Honeycombe, R. W. K. (1974). The Distribution of Boron in Pure Iron. Metal Science, 8(1), 317-324.

Calcagnotto, M., Adfachi, Y., Ponge, D., \& Raabe, D. (2014). Deformation and fracture mechanisms in fine -and ultrafine-grained ferrite/martensite dual- phase steels and the effect of aging. Acta Materalia, 59, 658-670.

Frank, A. R., \& Kirkcaldy, A. (1998). The effect of boron on the properties of electric arc-sourced plain carbon wiredrawing qualities. Wire Journal International, 5, 100-113.

Gorelik, S. S., Skakov, Y. A., \& Rastorguev, L. N. (1994). Radiographic and electron-optical analysis. Moskow: MICIC (in Russian).

Lyakishev, N. P., Pliner, Y. L., \& Lappo, S. I. (1986). Boron - contained Steels and Alloys. Moskow: Metallurgy (in Russian).

Parusov, V. V., Sychkov, A. B., Zhigarev, M. A., \& Perchatkin, A. V. (2004). Wire rod of boron bearing lowcarbon steel for direct deep drawing. Metallurgist., 48(11), 626-634.

Queiroz, R. R. U., Cunha, F. G. G., Gonzalez, B. M. (2012). Study of Dynamic Strain Aging in Dual - Phase Steel. Materials Science and Engineering, A(543), 84-87.

Shahriary, M. S., Koohbor, B., Ahadi, K., Ekrami, A., Khakian-Qomi, M., \& Izadyar, T. (2012). The effect of dynamic strain aging on room temperature mechanical properties of high martensite dual - phase (HMDP) steel. Materials Science and Engineering, A(550), 325 - 332.

Shevelev, A. K. (1966). A Study of the fine crystalline Structure and characteristic Temperature of B - alloyed Iron. Physics of Metals and Metallography, 22(2), 210-214.

Yalamanchili, B., Nelson, J., Power, P., \& Lanham, D. (2001). North Star Steel Texas's experience with boron additions to low-carbon steel. Wire Journal International, 11, 90-94.

McBride, C. C., Spretnak, J. E., \& Speiser, R. (1954). A. Study of the Fe-Fe ${ }_{2} B$ System. Trans. Am. Soc. Metals., 46, 499-524.

Mirkin, L. I. (1979). X-ray structure analysis control of machine-building materials. Book's Reference. Moskow: Machine - building (in Russian).

\section{Copyrights}

Copyright for this article is retained by the author(s), with first publication rights granted to the journal.

This is an open-access article distributed under the terms and conditions of the Creative Commons Attribution license (http://creativecommons.org/licenses/by/4.0/). 